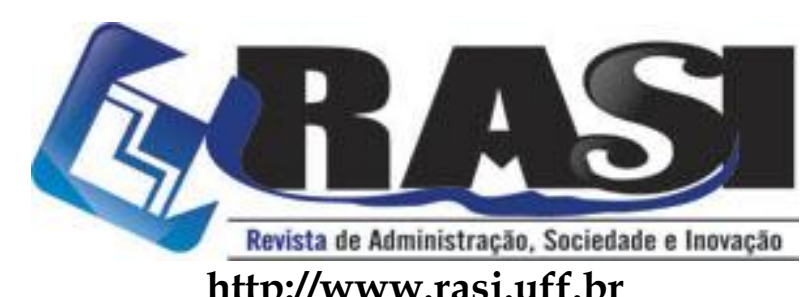

RASI, Volta Redonda/RJ, v. 3, n. 1, pp. 1-4, jan./jun. 2017.

\title{
Editorial: uma ponte entre rigor e relevância
}

Márcio Moutinho Abdalla

Universidade Federal Fluminense - UFF

marcioabdalla@id.uff.br

\section{Universidade \\ U⿴囗十⺝木 Federal \\ Fluminense}

R. Desembargador Ellis Hermydio Figueira, 783, Bloco A, sl. 304, Aterrado.

27213-145 - Volta Redonda, RJ - Brasil www.uff.br

Copyright @ 2017 RASI. Todos os direitos, até mesmo de tradução, são reservados. É permitido citar parte de artigos sem autorização prévia, desde que seja identificada a fonte. 


\section{Editorial: uma ponte entre rigor e relevância}

Caros leitores, orgulhosamente entregamos a quarta edição da Revista de Administração, Sociedade e Inovação - RASI. Revisitando nossos editorias anteriores (Abdalla, 2015, 2016a, 2016b), pude desfrutar de memórias interessantes, além de ter a oportunidade de aferir o curso de nossos planos. É relevante recordar que desde o nascimento da RASI, esboçamos oportunamente nossa preocupação com duas dimensões que, por vezes parecem figurar na academia de forma antagônica: o rigor e a relevância (e.g. Kieser \& Leiner, 2009). Essas dimensões naturalmente fomentam inquietações, temores e críticas acerca do estímulo ao produtivismo acadêmico (Mascarenhas, Zambaldi, \& Moraes, 2011; Vosgerau, Orlando, \& Meyer, 2017), sobretudo pelo crescente foco em modelos estatísticos suportados por sistemas informatizados, que modelam dados sob um formato de "caixa preta" e geram relatórios sintéticos, que são acriticamente exibidos em trabalhos científicos.

Apesar disso, continuamos acreditando na compatibilidade entre rigor e relevância, reforçando as preocupações destacadas em (Abdalla, 2016a), no que tange ao estudo de alternativas que maximizem a transparência dos trabalhos publicados pela RASI. Nesse sentido, abraçamos a ideia, proposta pelo amigo e professor Pítias Teodoro, da criação de uma seção (além das tradicionais - editorial e artigos), preliminarmente batizada de "replicáveis", que apresenta como principal atributo, a replicabilidade metodológica. Os trabalhos publicados nessa seção deverão extrapolar a (também relevante) discussão do tema, devendo detalhar tanto quanto possível, a descrição metodológica.

Compreendemos que um bom detalhamento metodológico deveria ser realizado em todos os trabalhos, no entanto, pretendemos abrir uma nova tendência em publicações no campo da administração, a partir da disponibilização pública da base de dados empregada pelo/a(s) pesquisador/a(es), tal qual é feito em algumas outras áreas do conhecimento (a exemplo da história). Acreditamos que a iniciativa apresenta consonância direta com o Manual de Boas Práticas da Publicação Científica da Anpad, além de prevenir situações como o famoso Caso Sokal. Nosso propósito com esta iniciativa é identificar, organizar e disponibilizar um conjunto de trabalhos, cujas descrições metodológicas sirvam, ao mesmo tempo, de inspiração e fonte de aprendizado e discussão para leitores e potenciais autores, na medida em que possam servir de modelos para elaboração de seus próprios trabalhos.

Esperamos submissões que atendam essa característica já para o próximo número. Antes de apresentarmos os trabalhos que compõem o número e nos valendo das novidades anunciadas, aproveitamos para enfatizar a importante mudança promovida pela atualização do sistema OJS (Open Journal Systems) para a versão 3.0. Tal mudança permitirá não apenas um visual mais agradável, associado a uma interface mais intuitiva, como também ganhos expressivos no processo editorial.

Na seção de artigos, abrimos essa edição com o trabalho "Projetos em Parcerias Intersetoriais: Uma análise sobre riscos e problemas", de Ralf Luis de Moura. A partir de uma abordagem qualitativa, o trabalho apresenta importantes contribuições, ao analisar projetos em parcerias intersetoriais e revelar quatro categorias de riscos com maior incidência por arena (ou parceria). 
O segundo trabalho, intitulado "Análise da Motivação dos Colaboradores do Batalhão de Operações Policiais Especiais - BOPE", de autoria de Carlos Patrick Barboza Gomes e Sheila Serafim da Silva, propõe um debate a respeito da motivação nessa instituição militar, a partir das principais teorias motivacionais que povoam o campo de conhecimento em administração.

No trabalho "Para Além do Lumpen-Indigenismo: novos aspectos informacionais da política indigenista brasileira", Rodrigo Piquet Saboia de Mello propõe uma releitura do trabalho "O lumpen-indigenismo do estado brasileiro", de Jorge Pozzobon, repensando questões, conceitos e propostas do autor.

Em “Adoção de Tecnologia na Organização: o caso de uma empresa brasileira do segmento de automação industrial", de autoria de Natan de Souza Marques, Aline Mariane de Faria, Roberto Sbragia e Bassiro Só, os autores analisam as formas pelas quais gestores de uma organização do segmento de automação industrial procedem suas decisões no que tange à adoção de tecnologia.

No quinto trabalho dessa edição, intitulado "O uso da Análise Relacional Grey como proposta de avaliação de empresas: um estudo em ambientes laboratoriais de gestão", os autores Camila Carvalho Oliveira Santos, Murilo Alvarenga Oliveira e Raphael Acosta Correio analisam equipes de um jogo de empresas a partir de três metodologias de avaliação: (i) taxa de retorno, (ii) EVA (valor econômico agregado) e (iii) um indicador produzido por meio da análise relacional Grey. O uso do indicador combinado Grey figura como relevante contribuição do trabalho, como forma complementar de avaliação de empresas.

Por fim, no último trabalho, Flaviana Medeiros Lameira Ribeiro se propõe a demonstrar como o uso de uma metodologia de compras públicas produziu ganhos substanciais na Prefeitura de São José do Vale do Rio Preto-RJ em seu artigo: "Sistema de Registro de Preços: um estudo de caso do uso do pregão no processo de compras de bens no município de São José do Vale do Rio Preto-RJ”.

Em nome da equipe editorial, desejo a todos uma excelente leitura!

Márcio M. Abdalla

Editor Chefe

\section{Referências}

Abdalla, M. M. (2015). Editorial: Construção de Conhecimentos - uma proposta pluriversal. Revista de Administração, Sociedade e Inovação, 1(1), 1-3.

Abdalla, M. M. (2016a). Editorial: A Salutar busca pela Transparência em Pesquisas. Revista de Administração, Sociedade e Inovação, 2(1), 1-3.

Abdalla, M. M. (2016b). Editorial: lições de um processo editorial. Revista de Administração, Sociedade e Inovação, 2(2), 87-89. 
Kieser, A., \& Leiner, L. (2009). Why the Rigour - Relevance Gap in Management Research Is Unbridgeable. Journal of Management Studies, 46(3), 516-533. https://doi.org/10.1111/j.1467-6486.2009.00831.x

Mascarenhas, A. O., Zambaldi, F., \& Moraes, E. A. de. (2011). Rigor, relevância e desafios da academia em administração: tensões entre pesquisa e formação profissional. Revista de Administração de Empresas, 51(3), 265-279. https://doi.org/10.1590/S0034-75902011000300007

Vosgerau, D. S. R., Orlando, E. de A., \& Meyer, P. (2017). Produtivismo Acadêmico e Suas Repercussões no Desenvolvimento Profissional de Professores Universitários. Educação \& Sociedade, 38(138), 231-247. https://doi.org/10.1590/es010173302016163514 